\title{
SOSIALISASI DAN PENYULUHAN TENTANG PENTINGNYA MENABUNG BAGI GENERASI MUDA KHUSUSNYA SISWA MADRASAH TSANAWIYAH MTS MATHLAUL ANWAR PAMULANG
}

\author{
Sri Mardiana, Wawan Supriyatna, Zakaria, Ratna Dumilah, Intan Sari Budhiarjo \\ Universitas Pamulang \\ Email:dosen02065@unpam.ac.id
}

\begin{abstract}
This PKM (The Community Dedication Program) was taken at the Madrasah Tsanawiyah MTs Mathlahul Anwar Pamulang, South Tangerang City. The problem that was taken came from the lack of knowledge of MTS students to save (money) at an early age. The extension program which provide by the trainer is expected to be able to provide knowledge about the importance of saving to the student. The PKM (The Community Dedication Program) is expected to be an opportunity for students to discuss the benefits of saving for the younger generation at MTs Mathlahul Anwar. Saving in a variety of perspectives is highly recommended because wasteful living habits will only leave difficulties in the future, in accordance with the motto of "saving is the base of the rich". The emphasis of the young generation on lifestyles (life style) actually fits well with the perspective of saving at this time, namely saving is part of the millennial lifestyle. With the provision of material related to the methods they learned, it really helped them understand that their money, owned by the student of MTs Mathlaul Anwar Pamulang Islamic Madrasah Tsanawiyah collected had to be spent for what and how they spend it, they even realized that the money was not only spent to provide an item but also can be a tool to help the lives of others. It is hoped that after being given an understanding of the importance of sheltering through material exposure by the Unpam lecturers, they can differentiate between necessities and desires. Then, they can learn how to treat in between these two items. They are very happy because from an early age they have been taught how to like to save and how to manage money.
\end{abstract}

Keywords: Financial Planning, Importance of Saving, Lifestyle

\begin{abstract}
Abstrak
PKM ini dengan mengambil lokasi di Madrasah Tsanawiyah MTs Mathlahul Anwar Pamulang Kota Tangerang Selatan. Permasalah yang diambil berasal dari kurangnya pengetahuan siswa - siswi MTS untuk menabung di usian dini. Program penyuluhan yang akan diberikan oleh narasumber diharapkan mampu memberikan pengetahuan mengenai pentingnya menabung kepada para siswa. Program PKM ini diharapkan menjadi kesempatan bagi para siswa untuk berdiskusi dengan narasumber terkait manfaat menabung bagi generasi muda di MTs Mathlahul Anwar.
\end{abstract}


Menabung dalam berbagai perspektif sangat dianjurkan karena kebiasaan hidup boros hanya akan menyisakan kesulitan dimasa depan, sesuai dengan semboyan hemat pangkal kaya. Penekanan generasi muda pada gaya hidup (life style) sebenarnya cocok sekali dengan perspektif menabung pada saat ini, yaitu menabung merupakan bagian dari gaya hidup generasi millenial. Dengan adanya pemberian materi terkait dengan adalah metode yang mereka pelajari sangat membantu mereka memahami bahwa uang yang para siswa Madrasah Tsanawiyah MTs Mathlaul Anwar Pamulang kumpulkan itu harus dilakukan untuk apa dan seperti apa, bahkan mereka menyadari bahwa uang itu tidak hanya diperankan untuk memberikan suatu barang tapi juga bisa menjadi alat membantu kehidupan orang lain. Diharapkan setelah diberikan pemahaman pentingnya menaung melalui paparan materi oleh para dosen Unpam mereka bisa membedakan mana barang kebutuhan dan mana barang keinginan. Lalu, mereka bisa belajar menyikapi dalam memperlakukan diantara kedua barang tersebut. Mereka sangat senang karena sejak dini sudah diajari menerapkan perilaku gemar menabung dan cara mengelola uang

Kata Kunci: Perencanaan Keuangan, Pentingnya Menabung, Gaya Hidup

\section{A. PENDAHULUAN}

Pada masa sekarang tabungan tidak hanya berfungsi sebagai penyimpan uang, lebih jauh lagi menabung membuat seseorang memiliki akses kepada perbankan digital dan segala sesuatu yang berkaitan dengan keuangan digital. Menabung tidak lagi disetor secara maual ke teller pada cabang bank tertentu, tetapi sudah bisa dilakukan secara otomatis di mesin mesin ATM setor-tarik, juga dapat dilakukan pada mitra bank UKM disekitar rumah. Penekanan generasi muda pada gaya hidup (life style) sebenarnya cocok sekali dengan perspektif menabung pada saat ini, yaitu menabung merupakan bagian dari gaya hidup. Dengan menabung, para remaja tersebut dapat keuntungan dari lifestyle yang mereka lakukan, yaitu manfaat menabung dalam digital banking. Mereka dapat melakukan pembelian pulsa, kuota internet, token listrik. Mereka dapat membantu orang tua mereka dengan digital banking, diataranya bisa melakukan pembayaran BPJS, cicilan motor, cicilan pinjaman dan sebagainya, bahkan membeli makanan dan minuman akan lebih hemat jika menggunakan uang electronik yang hanya dapat di topup dengan mudah jika memiliki rekening di bank tertentu. Tabungan atau simpanan merupakan istilah yang sudah tidak asing lagi biasa kita dengar, tabungan adalah simpanan yang penarikannya dapat dilakukan sewaktu-waktu sesuai dengan syarat dan ketentuan yang telah disepakati sedangkan Menabung adalah suatu kegiatan atau aktifitas yang dilakukan dalam rangka menyimpan atau menyisihkan uang. Menabung merupakan kegiatan yang baik untuk dipupuk sejak dini, karena dengan melatih menabung dapat memberikan dampak positif untuk kehidupan mendatang. Oleh sebab itu alangkah baiknya mulai mengenalkan sejak dini kegiatan atau aktifitas menabung untuk anak-anak.Kegiatan tersebut dapat 6 dimulai dengan hal-hal kecil dimana si anak diarahkan 
untuk dapat menyisihkan uang jajannya dan memasukan sisa uang jajan tersebut ke dalam celengan. Dengan menerapkan kebiasaan positif tersebut diharapkan dapat memberikan dampak positif kepada anak sebagai berikut : 1. Anak diajarkan sejak dini untuk belajar mengatur keuangan 2. Anak diajarkan skala prioritas mana yang penting dan tidak penting 3 . Anak diajarkan untuk lebih menghargai uang 4. Anak diajarkan sifat mandiri dan konsisten untuk dapat mencapai suatu keinginan Memiliki Kebiasaan menabung sudah jelas sangat berguna untuk masa depan kita. Menabung atau disimpan maka akan semakin baik menyimpan sejumlah uang agar dapat digunakan di kemudian hari jika diperlukan. Semakin banyak duit yang ditabung maka akan semakin baik. Oleh karena itu Kegiatan sosialisasi sejak dini adalah kegiatan yang cukup penting agar dapat tercapainya pemahaman kepada anak-anak bahwa menabung sangat bermanfaat bagi masa depan sehingga dapat memotivasi anak dalam menabung dan timbulnya kesadaran anak-anak untuk dapat menyisihkan sebagian uang jajan mereka agar dapat ditabung.Pentingnya pemahaman arti dan fungsi uang bagi anak usia dini. Menabung merupakan hal baru yang bisa diterapkan sekaligus dimengerti oleh anak usia dini.Menabung merupakan hal yang bisa diterapkan sekaligus dimengerti oleh anak usia dini, tergantung bagaimana cara anda memberikan pengertian. Akan tetapi ada halyang harus anda lakukan, yaitu memberikan pengertian tentang uang beserta manfaatnya.

Dari dampak positif diatas maka dapat disimpulkan bahwa menabung merupakan kegiatan yang sangat bermanfaat baik untuk hari ini terlebih untuk masa yang akan datang karena hasil yang ditabung dapat dirasakan dimasa yang akan datang. Berikut sebagian kecil dari manfaat menabung 1. Membiasakan menyisihkan uang 2. Membiasakan mengatur dan mengelola keuangan 3. Mendisiplinkan perencanaan keuangan 74 . Sudah merencanakan dan mempersiapkan masa depan Dari empat hal tersebut diatas, menabung memiliki peranan yang cukup penting untuk masa depan,karena dengan menabung membiasakan kita untuk mengelola keuangan dan mempersiapkan masa depan yang lebih baik maka semakin banyak uang yang disisihkan dan disimpan untuk nantinya diinvestasikan maka akan semakin baik masa depan kita. Kegitan sosialisasi atau menerapkan menabung sejak dini adalah kegiatan yang cukup penting agar dapat dipahami dan dimulai oleh anak-anak, dimana menabung sangat bermanfaat untuk masa depan, menyadarkan dan memotivasi mereka untuk dapat menyisihkan uang atau menghargai uang sejak dini dapat dilakukan dengan sebelumnya memberikan pengertian terlebih dahulu.

Mitra dalam PKM kali ini, yaitu para pelajar yang ada di Madrasah Tsanawiyah MTs Mathlaul Anwar Pamulang. Mereka dianggap sudah mampu untuk mengelola sendiri segala sesuatu yang mereka dapatkan dari para orang tua mereka, termasuk mengatur masalah keuangan mereka. Pola hidup remaja sekarang sudah sangat jauh berbeda dengan nilai - nilai yang dulu diterapkan oleh para orangtua kita. Budaya serba instant yang terdapat disekitar seolah menuntun mereka untuk serba instant, termasuk dalam urusan keuangan, pelajaran maupun dalam menghadapi suatu masalah (problem solving). Madrasah Tsanawiyah (MTs) Mathlaul Anwar Pamulang merupakan sebuah lembaga pendidikan yang berada di Tangerang Selatan, tepatnya di Jl. H. Rean No.111, RT.03/RW.01, Benda Baru, Kec. Pamulang, Kota Tangerang Selatan, Banten 15415. 
Kegiatan ini dilaksanakan sebagai awal kegiatan dengan tujuan untuk memperoleh deskripsi kondisi komunitas yang dituju; yaitu dengan mengadakan pertemuan dengan Kepala sekolah Madrasah Tsanawiyah (MTs) Mathlaul Anwar Pamulang yaitu Bapak. Komarudin, S.Th.I. menyatakan bahwa siswa - siswi masih membutuhkan penyuluhan secara intensif tentang pentingnya menabung supaya tumbuh budaya menabung sejak dini.

\section{B. METODE PELAKSANAAN KEGIATAN}

Tujuan kegiatan pengabdian kepada masyarakat ini adalah untuk meningkatkan pengetahuan anak-anak pelajar di Madrasah Tsanawiyah MTs Mathlaul Anwar Pamulang terhadap Pentingnya Menabung Sejak Usia Dini.

Metode kegiatan pengabdian kepada masyarakat yang digunakan adalah memberikan penyuluhan dan mensosialisasikan tentang pentingnya menabung. Sehubungan masih dalam masa PSBB di wilayah Tangerang Selatan maka metode yang di gunakan dalam kegiatan Pengabdian Kepada Masyarakat ini adalah dengan Webinar menggunakan aplikasi Zoom Meeting.

Metode dalam pelaksanaan kegiatan pengabdian ini dilakukan dalam beberapa tahap, yaitu:

1. Tahap Observasi

Kegiatan ini dilaksanakan sebagai awal kegiatan dengan tujuan untuk memperoleh deskripsi kondisi komunitas yang dituju; yaitu dengan mengadakan pertemuan dengan Kepala sekolah Madrasah Tsanawiyah (MTs) Mathlaul Anwar Pamulang yaitu Bapak. Komarudin, S.Th.I.

2. Tahap Sosialisasi

Dalam tahap ini, tim pengabdian akan memberikan dan menjelaskan rencana pengabdian yang akan dilakukan sehingga dapat diatur waktu dan berbagai keperluan teknis sehubungan dengan pelaksanaan pelatihan secara keseluruhan.

3. Tahap Pelaksanaan Penyuluhan

Pelaksanaan pengabdian kepada masyarakat ini dilakukan dengan kerjasama dari pihak Madrasah Tsanawiyah (MTs) Mathlaul Anwar Pamulang. Dalam penyuluhan ini, siswa - siswi tersebut akan diberikan penjelasan tentang pentingnya menabung demi tercapainya cita-cita mereka di masa mendatang. Program Pengabdian Kepada Masyarakat yang kami lakukan di Madrasah Tsanawiyah (MTs) Mathlaul Anwar Pamulang terkait halhal berikut:

1. Mengenalkan budaya menabung pada anak-anak pelajar Madrasah Tsanawiyah (MTs) Mathlaul Anwar Pamulang Tangerang Selatan.

2. Melatih mengatur keuangan mereka sendiri khususnya anak-anak lingkungan Madrasah Tsanawiyah (MTs) Mathlaul Anwar Pamulang untuk menabung sejak usia dini.

3. Mendidik anak-anak agar mampu memperhitungkan berapa uang jajan dan berapa uang yang harus di simpan. 


\section{B. HASIL DAN PEMBAHASAN}

\section{Tahap Observasi}

Tahap observasi ini dilakukan sebanyak dua kali kunjungan. Kunjungan pertama dilakukan untuk menemui kepala sekolah dan wali kelas dan guru Madrasah Tsanawiyah (MTs) Mathlaul Anwar Pamulang untuk mengetahui kebutuhan anak anak usia puberitas berkenaan dengan perilaku gemar menabung. Disamping itu, beberapa siswa - siswi Madrasah Tsanawiyah (MTs) Mathlaul Anwar Pamulang juga memberikan informasi tentang kebutuhan pembelajaran mengenai strategi dan upaya penerapan gemar menabung bagi teman - temannya untuk masa waktu minimal 1 tahun. Pada kunjungan kedua, observasi dilakukan dengan wawancara secara informal kepada anak-anak usia masa puberitas di lokasi setempat terutama dalam pemahaman tentang perilaku gemar menabung. Pada umumnya mereka merasa perlu tahu pola penerapan perilaku gemar menabung sehingga mereka mempunyai uang tabungan. Pada kesempatan ini tim pengabdian masyarakat mendapatkan informasi mengenai tema apa saja yang dapat dipersiapkan untuk pelatihan nantinya. Berdasarkan hasil observasi secara informal tersebut maka diketahui bahwa anak-anak usia masa puberitas lebih membutuhkan keterampilan dalam menerapkan perilaku gemar menabung dapat diketahui bahwa selama ini mereka masih sangat sulit dalam melakukan penerapan perilaku gemar menabung. Setelah itu, TIM PKM yang terdiri dari lima orang Dosen UNPAM melakukan Forum Group Discussion (FGD) untuk mempersiapkan pelaksanaan Pengabdian Kepada Masyarakat (PKM) di Madrasah Tsanawiyah (MTs) Mathlaul Anwar Pamulang Tangerang Selatan yang di laksanakan secara online melalui aplikasi Zoom.

\section{Tahap Sosialisasi}

Sosialisasi ini terlaksana pada bulan Maret awal. Tahap ini dilakukan sebanyak dua kali kunjungan. Pada kunjungan pertama, tim pengabdian masyarakat memberikan surat pengantar dan penjelasan kepala sekolah Madrasah Tsanawiyah (MTs) Mathlaul Anwar Pamulang setempat, Bapak Komarudin, S.Th.I sehingga mereka nanti bisa menyampaikan maksud dan tujuan kegiatan ini kepada anak-anak usia masa puberitas ini, yang diwakili oleh orang tua masing masing. Kunjungan kedua dilakukan sebagai upaya mengetahui konfirmasi dari pihak Madrasah Tsanawiyah (MTs) Mathlaul Anwar Pamulang yang diwakili oleh kepala sekolah Madrasah Tsanawiyah (MTs) Mathlaul Anwar Pamulang Bapak Komarudin, S.Th.I mengenai jadwal kegiatan, yang berkenaan dengan hari dan waktu pelaksanaan kegiatan, latar belakang para peserta, jumlah peserta, dan persiapan materi.

\section{Tahap Pelaksanaan Pengabdian}

Tahap ini dilaksanakan pada tanggal 3-4 Juli 2020, sebanyak dua kali pertemuan. Setiap pertemuannya berlangsung selama 90 menit. Materi yang diberikan berdasarkan buku teks berjudul "Financial Parenting: Menjadikan Anak Cerdas dan Cermat Mengelola Uang" karangan kak Seto dan Lutfi Trizki, serta sumber primer lainnya. Materi yang diberikan untuk pelatihan strategi dan upaya penerapan perilaku gemar menabung meliputi (1) Siapkan 
Celengan yang kamu sukai (2) Langsung menyisikan sebagian ketika dikasih uang jajan (3) Beri tahu mama papa kamu, saat kamu sudah mulai menabung (4) Uang yang kamu tabung tidak harus 18 dari orang tua (5) orang - orang sukses itu diawali dengan pengalaman rajin menabung, bekerja dan berdoa (6) Jika punya impian maka kerja keras dan menabung dulu (7) Menabung menghindari kita dari cicilan (8) Menabung bisa di sekolah, Bank, atau lembaga keuangan lainnya. Kegiatan ini di ketuai oleh Bapak Wawan Supriyatna, S. Kom., M.M dengan narasumber Bapak Zakaria, S.Sos, M.M dan Ibu Sri Mardiana, S.E., M.M serta dibantu dosen UNPAM lainnya yaitu Ibu Ratna Dumilah, S.E., M.M selaku Moderator dan Ibu Intan Sari Budhiarjo, S.E., M.M. selaku Host. Kegiatan PKM ini diikuti oleh siswa siswi kelas 7 yang ada di Madrasah Tsanawiyah (MTs) Mathlaul Anwar Pamulang Tangerang Selatan. Dengan tahap pelaksanaan sebagai berikut:

Sesi I

Tanggal 3 Juli 2020: Dalam sesi ini durasi kegiatan Pengabdian Kepada Masyarakat selama 90 menit.

Dengan memberikan materi: Pentingnya menabung sejak dini dan di lanjutkan dengan sesi Tanya Jawab.

Sesi II

Tanggal 4 Juli 2020: Dalam sesi ini durasi kegiatan Pengabdian Kepada Masyarakat selama 90 menit.

Dengan memberikan materi: Pentingnya menabung untuk kebutuhan mendesak di lanjutkan dengan sesi Tanya Jawab dan terakhir Pemberian Sovenir.

\section{KESIMPULAN DAN SARAN}

\section{Simpulan}

Pelaksanaan kegiatan Pengabdian Kepada Masyarakat oleh Lembaga Penelitian dan Pengabdian Masyarakat (LPPM) Universitas Pamulang yang dilakukan oleh dosen-dosen program studi Manajemen sudah berjalan dengan lancar. Dengan adanya pemberian materi sangat membantu siswa - siswi dalam memahami bahwa uang yang mereka miliki tidak hanya digunakan untuk memberikan suatu barang tapi juga dapat membantu kehidupan orang lain. Harapan kami dengan pengabdian ini dapat menambah ilmu yang bermanfaat dalam hal pengenalan budaya menabung sejak dini dan mereka menjadi paham dalam membedakan mana barang kebutuhan dan mana barang keinginan.

Dalam laporan kegiatan ini mungkin banyak kekurangan yang ada, untuk itu kami berharap masukan dan kritikan dalam rangka perbaikan untuk kegiatan-kegiatan pengabdian masyarakat di masa yang akan datang. Semoga kegiatan pengabdian masyarakat ini dapat bermanfaat bagi masyarakat sekitar lingkungan Universitas Pamulang dan lainnya.

Akhirnya, kami mengucapkan terima kasih kepada seluruh pihak yang telah mendukung kegiatan yang kami laksanakan dan kami mohon maaf apabila dalam laporan ini banyak ditemukan kekurangan. 


\section{Saran}

Berdasarkan hasil kegiatan Pengabdian Kepada Masyarakat, maka kami dari Tim Dosen Universitas Pamulang memberikan saran diantaranya sebagai berikut:

1. Untuk siswa - siswi Madrasah Tsanawiyah (MTs) Mathlaul Anwar Pamulang diharapkan rutin melakukan tahapan yang sudah di berikan saat pemaparan materi pelatihan Pengabdian Kepada Masyarakat berlangsung. Sehingga ilmu yang di dapatkan selalu berguna untuk saat ini dan masa mendatang.

2. Adanya kontribusi dari pihak universitas untuk bisa memberikan fasilitas dalam pelayanan kepada masyarakat dalam bentuk sarana dan prasarana.

\section{Ucapan Terima Kasih}

Rasa syukur dan suka cita kami sampaikan kepada segenap pihak yang telah mensukseskan kegiatan PKM dengan judul “ Sosialisasi Dan Penyuluhan Tentang Pentingnya Menabung Bagi Generasi Muda Khususnya Siswa-siswi Madrasah Tsanawiyah Mathlaul Anwar Pamulang” yaitu:

1. Rektor Dr. H. Dayat Hidayat, M.M, Rektor Universitas Pamulang Tangerang Selatan Banten.

2. Dr. Ali Maddinsyah, S.E., M.M., selaku Ketua LPPM Universitas Pamulang Tangerang Selatan - Banten.

3. Dr. Kasmad, S.E., M.,M., selaku Ketua Program Studi Manajemen Universitas Pamulang Tangerang Selatan - Banten.

4. Dr. Udin Ahidin, S.E., M.M., C.M.A, Selaku Wakil Program Studi Manajemen Universitas Pamulang Tangerang Selatan - Banten.

5. Drs. Waluyo Jati, M.M., Selaku Sekretaris Program Studi Manajemen Universitas Pamulang Tangerang Selatan - Banten.

6. Komarudin, S.Th.I, selaku Kepala Sekolah Madrasah Tsanawiyah MTs Mathlaul Anwar Pamulang

7. Mahasiswa Universitas Pamulang yang juga ikut berkontribusi terhadap kelancaran kegiatan PKM.

8. Siswa - siswi kelas 7 Madrasah Tsanawiyah MTs Mathlaul Anwar Pamulang.

\section{DAFTAR PUSTAKA}

Artikel Perencanaan Keuangan Keluarga, Langkah Pertama Menuju Kebahagiaan, 12 Februari 2019

Beth Kobliner, (2017). Make Your Kid A Money Genius

Gozali, Ahmad. (2016). Habiskan Saja Gajimu. Transmedia Pustaka: Jakarta

Ghozie, Prita H. (2016). Make It Happen! Buku Pintar Rencana Keuangan

Hanafi, (2012) Manajemen Keuangan, Yogyakarta: BPFE

Https://mathlaulanwar.or.id/ 
Http://emispendis.kemenag.go.id/dashboard/

Ikatan Akuntan Indonesia, (2007) (Revisi 2009), PSAK No. 23 Pengakuan Pendapatan, Salemba Empat, Jakarta.

Solihin, D. (2020), Pengaruh Kepercayaan Pelanggan dan Promosi Terhadap Keputusan Pembelian Konsumen Pada Online Shop Mikaylaku Dengan Minat Beli Sebagai Variabel Intervening. JURNAL MANDIRI: Ilmu Pengetahuan, Seni, dan Teknologi, Vol. 4, No. 1.

Solihin, D. (2020), Faktor-Faktor yang Mempengaruhi Kinerja Pemasaran Pada PT. Prima Ufuk Semesta Studi Pada Outlet Rekanan PT. Prima Ufuk Semesta di Wilayah JABODETABEK, Jurnal Semarak, Vol. 3 No.1.

Solihin, D. (2020), Pengaruh Kualitas Pelayanan, Harga, Dan Promosi Terhadap Keputusan Pelanggan Dalam Memilih Klub Basket Satria Indonesia Tangerang Selatan, Jurnal Pemasaran Kompetitif, Vol. 3, No. 3.

Solihin, D. (2019), Pengaruh Current Ratio dan Debt to Equtity Ratio Terhadap Return on Asset (ROA) Pada PT. Kalbe Farma Tbk. Jurnal Kreatif, Vol. 7. No. 1.

Solihin, Ismail. (2012). Manajemen Strategik. Penerbit Erlangga : Bandung. 